\title{
Review of the effusus group of the Lanternfly genus Pyrops Spinola, 1839, with one new species and notes on trophobiosis (Hemiptera: Fulgoromorpha: Fulgoridae)
}

\author{
Jérôme CONSTANT \\ Royal Belgian Institute of Natural Sciences, O.D. Phylogeny and Taxonomy, Entomology, Vautier \\ street 29, B-1000 Brussels, Belgium. E-mail: jerome.constant@naturalsciences.be \\ urn:Isid:zoobank.org:author:6E6072A1-9415-4C8D-8E60-2504444DB290
}

\begin{abstract}
The species group effusus of the genus Pyrops Spinola, 1839 is reviewed and the nomenclatural history of the genus Pyrops is briefly summarized. One new species from eastern Borneo, Pyrops synavei sp. nov., is described. P. gunjii (Satô \& Nagai, 1994) stat. nov. is proposed as a valid species instead of a subspecies of P. whiteheadi (Distant, 1889). P. maquilinganus (Baker, 1925) is removed from the effusus group and placed back into the candelaria group. P. cyanirostris (Guérin-Méneville, 1845) is removed from the group and not attributed to any of the currently defined species groups. An illustrated key to the species of the group with the addition of $P$. intricatus (Walker, 1857) and a distribution map are given. The effusus group is restricted to Borneo and adjacent Laut Island and presently contains 4 species: P. effusus (Distant, 1891), P. gunjii (Satô \& Nagai, 1994) stat.nov., P. synavei sp. nov. and P. whiteheadi (Distant, 1889). Trophobiosis observations with the gecko Gehyra mutilata (Wiegmann, 1835) (Reptilia: Squamata: Gekkonidae) and two species of cockroaches (Insecta: Blattodea), one Dorylaea sp. and an unidentified species of Pseudophyllodromiinae, are reported and illustrated for P. whiteheadi; observation with a cockroach, Dorylaea sp., is reported for P. intricatus.
\end{abstract}

Keywords. Indonesia, Malaysia, Lanternfly, Fulgoroidea, citizen science

Constant J. 2015. Review of the effusus group of the Lanternfly genus Pyrops Spinola, 1839, with one new species and notes on trophobiosis (Hemiptera: Fulgoromorpha: Fulgoridae). European Journal of Taxonomy 128: 1-23. http://dx.doi.org/10.5852/ejt.2015.128

\section{Introduction}

The Lanternfly genus Pyrops Spinola, 1839 contains colourful, spectacular and popular species which are immediately recognized as Lanternflies by all entomologists because of their typical cephalic process. It is widely distributed in the Indomalayan region, from Sri Lanka to the Himalayas (north India, south China), eastwards to Taiwan and Vietnam, and southwards to Sulawesi and neighbouring islands through Indonesia and the Philippines. It currently covers 58 species and 16 subspecies (Bourgoin 2015), but despite the publication of revisions and catalogues (e.g., Lallemand 1963; Nagai \& Porion 1996) its taxonomy is far from comprehensively resolved and still contains many errors and inconsistencies (Constant, unpublished). 
The genus was divided into 5 species groups by Baker (1925) [at the time under the genus name Fulgora Linnaeus, 1767], a view followed by Lallemand (1963) [also under Fulgora] and by Nagai \& Porion, 1996, both of the latter with minor changes.

The issue concerning the inconsistent use of the genus names Fulgora Linnaeus, 1767, Pyrops Spinola, 1839 and Laternaria Linnaeus, 1764, despite the wise treatment proposed by Kirkaldy (1902), was finally fixed in a similar way by a decision of the International Commission on Zoological Nomenclature (1955), who designated Cicada laternaria Linnaeus, 1758 as the type-species of the genus Fulgora, which is restricted to the Neotropics (the "peanut-headed lanternflies"). It also suppressed the genus name Laternaria because its type species was also Cicada laternaria. Consequently, the genus name Pyrops, with Cicada candelaria Linnaeus, 1758 as type-species, validly grouped the species of SouthEast Asia related to candelaria. However Lallemand (1960a,b, 1963), Chou et al. (1985) and Satô \& Nagai (1994) continued erroneously using Fulgora instead of Pyrops. Nagai \& Porion (1996) correctly used Pyrops for all species of SE Asia, but left species epithets feminine, an error corrected later by Liang (1998), who erroneously stated that he proposed new combinations (most probably because he was not aware of Nagai \& Porion's (1996) work) and that the decision of the International Commission on Zoological Nomenclature (1955) contained a formal designation of the genus name Pyrops for the species of the Oriental region. Sadly enough, some recent papers still contain and spread incorrect use of the name Laternaria, e.g., Leong et al. (2009), who even state that the use of Pyrops is incorrect because of the priority of Laternaria (sic!), or Kemal \& Koçak (2012).

The effusus group in the genus Pyrops Spinola, 1839 was erected by Baker (1925), at that time as the effusa group in Fulgora. He defined the effusus group for medium to small sized species sharing characters such as the shape of the cephalic process, which is "very short but not very stout", apically more or less swollen or vertically expanded, in most cases strongly bent or curved upwards and at least partly bright blue-green. The tegmina are greenish basally with various yellowish dots or markings, and castaneous apically, the hind wings blue basally and broadly black apically. He included 3 species in the group: P. effusus (Distant, 1891), P. viridicastaneus (Baker, 1925) and P. transversolineatus (Baker, 1925), the latter two species described in the same paper. He actually erroneously identified specimens of $P$. whiteheadi (Distant, 1889) under the name effusus and redescribed $P$. effusus as a new species, $P$. viridicastaneus. The placement of $P$. transversolineatus in the group is strange as the shape of the head does not match the characters given for the group and the author even mentioned similarities with the genera Saiva Distant, 1906 and Prolepta Walker, 1851 or with two species he placed in the candelaria group: Pyrops maquilinganus (Baker, 1925) and P. delesserti (Guérin-Méneville, 1840).

Lallemand (1963) renamed Baker's (1925) effusus group "quatrième groupe: type whiteheadi", most probably because he synonymized effusus under whiteheadi. He restricted the characters of the group to those of the cephalic process: less than $12 \mathrm{~mm}$ long, rounded apically, forming a little ball and more or less club-shaped. He included 4 species in the group: P. maquilinganus (Baker, 1925), P. dimotus (Lallemand, 1960), P. sapphirinus (Schmidt, 1908) and P. whiteheadi. He transferred P. transversolineatus to the genus Saiva Distant, 1906 and synonymized $P$. effusus and $P$. viridicastaneus with $P$. whiteheadi. He also mentioned that $P$. dimotus shows intermediate characters between Saiva and Pyrops, and that it might only be a variety of $P$. sapphirinus. Finally, he stated that whiteheadi was a variable species and that in the series of specimens he had identified as whiteheadi from eastern Borneo, one perfectly matched the description of $P$. effusus while another matched that of viridicastaneus. Strangely enough, that statement seems to have been given to justify the synonymy of effusus and viridicastaneus with whiteheadi. Actually, Lallemand's collection contains 2 specimens of $P$. effusus erroneously identified by him as $P$. whiteheadi. Accordingly, the male genitalia illustrated in Lallemand's (1963) work (pl. X, figs 11-13) and erroneously attributed to $P$. whiteheadi, pertain to $P$. effusus. 
CONSTANT C., Fulgoridae: Pyrops effusus species group (Hemiptera)

Satô \& Nagai (1994) described and illustrated Fulgora whiteheadi gunjii from Borneo, perpetuating the erroneous use of Fulgora instead of Pyrops, and considered viridicastaneus Baker, 1925 as a subspecies of $P$. whiteheadi.

Nagai \& Porion (1996) followed the classification proposed by Lallemand (1963), but correctly used Pyrops as a genus name. In the "groupe IV", as defined by Lallemand, they included 3 species and one subspecies: P. cyanirostris (Guérin-Méneville, 1845), P. maquilinganus, $P$. whiteheadi and $P$. whiteheadi gunjii. They synonymized dimotus and sapphirinus with cyanirostris, and followed Lallemand in considering effusus and viridicastaneus as junior synonyms of whiteheadi. They illustrated the types of $P$. dimotus, $P$. effusus, $P$. whiteheadi and $P$. whiteheadi gunjii, as well as specimens of $P$. cyanirostris, $P$. maquilinganus and one specimen of $P$. effusus from Lallemand's collection erroneously cited under the name $P$. whiteheadi.

Later, in 2004, Nagai \& Porion reconsidered the nomenclature of $P$. whiteheadi and its synonyms and illustrated specimens of $P$. whiteheadi and $P$. effusus. They reinstated $P$. effusus as a valid species with $P$. viridicastaneus as a junior synonym. They erroneously mentioned 1960 instead of 1963 as the date of publication of Lallemand's revision.

The present paper aims at clarifying the nomenclature and proposing an accurately illustrated identification key for the species of the group, and at describing a new species from eastern Borneo. The current knowledge of the distribution of the species of the effusus group is illustrated by a map.

The updated nomenclature of all cited taxa will be documented in FLOW (Bourgoin 2015).

\section{Materials and methods}

Type specimens of all species have been examined. The male genitalia were dissected as follows: the pygofer was cut from the abdomen of the softened specimen with a needle blade, then boiled for about one hour in a $10 \%$ solution of potassium hydroxide $(\mathrm{KOH})$. The phallic complex was dissected with a needle blade and all pieces examined in ethanol, the whole placed in glycerine for preservation. Observations were done with a Leica MZ8 stereo-microscope. Pictures were taken with a Canon EOS 300 D camera with Sigma DG Macro lens and optimized with Adobe Photoshop CS3. Inflation of the phallus was not performed due to the difficulty of obtaining good and replicable results and because it is not indispensable to separate the species in the genus Pyrops.

For the transcription of the labels of the types, the wording on each single label is given in square brackets.

The measurements were mainly taken as in Constant (2004) and the following abbreviations are used:

$\mathrm{BF}=$ breadth of the frons

$\mathrm{BTg}=$ breadth of the tegmen

$\mathrm{BPrH}=$ breadth of the cephalic process at half length

$\mathrm{LF} \quad=$ length of the frons

$\mathrm{LTg}=$ length of the tegmen

$\mathrm{LPr}=$ length of the cephalic process

$\mathrm{TL}=$ total length

(LF, LPr and TL measured to/from ante-ocular carina at the base of the cephalic process)

In the results section, species are treated in alphabetical order. 


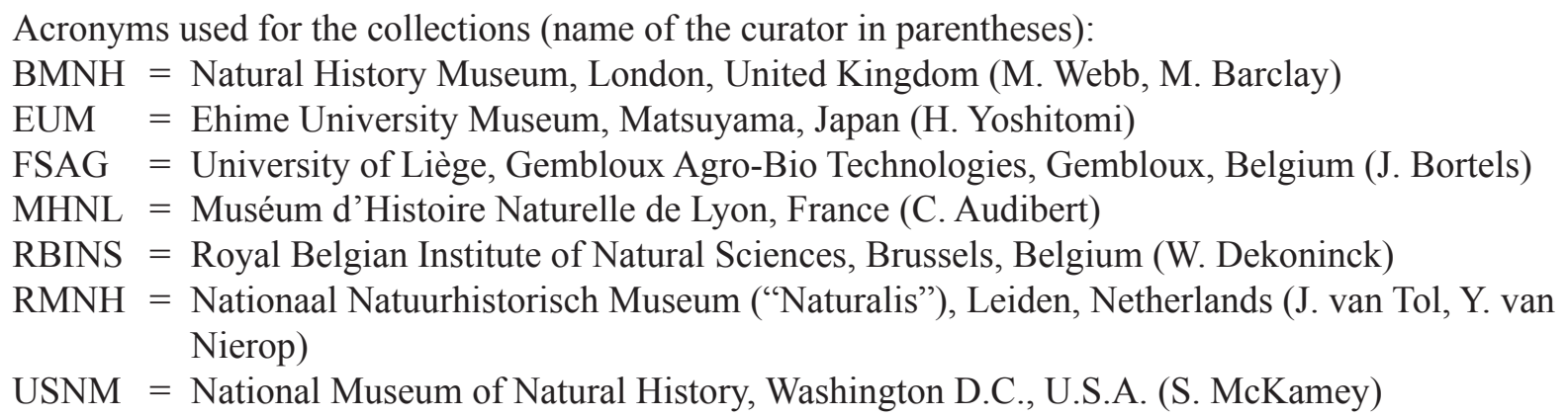

\section{Results}

Class Hexapoda Blainville, 1816

Order Hemiptera Linnaeus, 1758

Suborder Auchenorrhyncha Duméril, 1806

Infraorder Fulgoromorpha Evans, 1946

Superfamily Fulgoroidea Latreille, 1807

Family Fulgoridae Latreille, 1807

Genus Pyrops Spinola, 1839

Pyrops Spinola, 1839: 231. Type species: Pyrops candelaria (Linnaeus, 1758) by subsequent designation by Duponchel (1840: 200).

Hotinus Amyot \& Serville, 1843: 490 [synonymized by Blanchard 1845: 425]. Type species: Pyrops candelaria (Linnaeus, 1758) by original designation.

\section{Diagnostic characters}

The characters defining the genus as given by Lallemand (1963) under Fulgora are here slightly modified, i.e., head with cephalic process, sometimes very long, narrowing progressively beyond the eyes; apically it can be dilated or even spherical. Vertex about 4 times as broad as an eye. Before eyes, genae truncate with a transverse carina which sometimes extends to vertex. Two longitudinal carinae on frons, a third median one starting on base of cephalic process. Fronto-clypeal suture usually slightly bisinuate; median carina on clypeus. Pronotum with median carina (sometimes obsolete) and a small but strongly impressed point on each side of it. Mesonotum with median and peridiscal carinae, sometimes obsolete. Tegmina at most 3 times as long as broad, with apical margin more or less rounded and with transverse veinlets on all surfaces. Clavus open and elongate, vein $\mathrm{A} 1+\mathrm{A} 2$ extending far towards apex. Legs slender.

\section{The effusus species group}

The characters of this very consistent group mainly follow Baker's (1925: 348) definition: (1) medium sized species; (2) cephalic process very short, clavate, bent in middle, strongly curved upwards, and with at least apical half blue or green; (3) tegmina green or blue basally, with yellow dots or markings; (4) hind wings blue basally and broadly black apically, the black colour extending towards the base along the main veins; (5) legs brown.

As compared to the list of included species given by Nagai \& Porion(1996), Pyrops cyanirostris (GuérinMéneville, 1845) and P. maquilinganus (Baker, 1925) are here removed from the effusus group, the first because it does not match characters (3) and (4), the latter because it does not match characters (2), (4) and (5). P. maquilinganus is returned to the candelaria group as originally proposed by Baker (1925); $P$. cyanirostris cannot be attributed to any of the currently defined species groups in Pyrops. 
All 4 species included here in the group are restricted to Borneo and adjacent islands. Noteworthy, $P$. cyanirostris is recorded from Java (Guérin-Méneville 1845) and Sumatra (Nagai \& Porion 1996) and $P$. maquilinganus from the Philippines (Baker 1925).

The group seems to be close to the pyrorhynchus species group which shares characters (3) and (4), but contains large sized species with an elongate cephalic process. However, the cephalic process in the latter group is also bent in the middle - even if not so strongly curved upwards - and slightly dilated apically like in effusus group. In some way the members of the effusus group could be regarded as dwarfed members of the pyrorhynchus group.

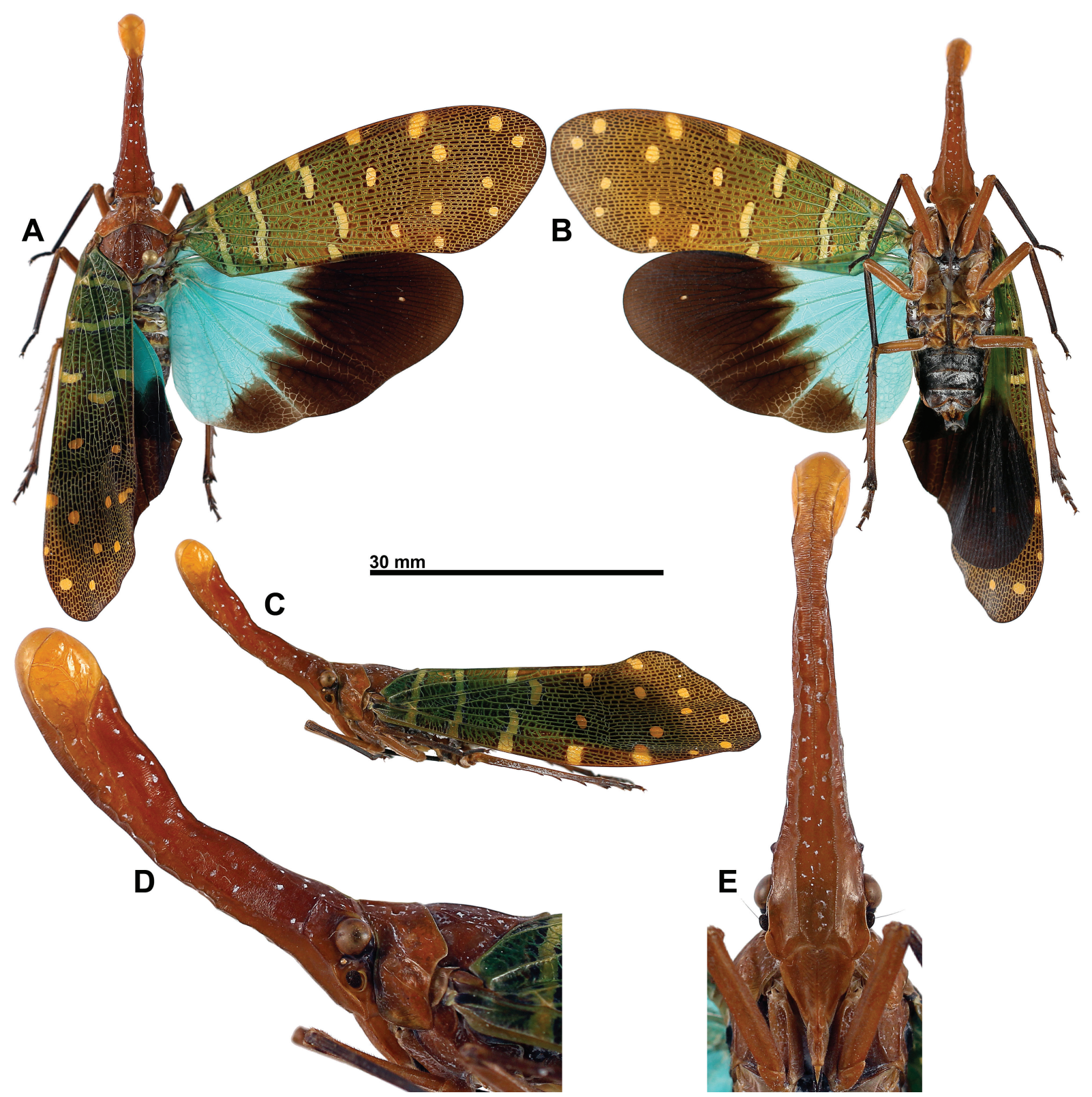

Fig. 1. Pyrops intricatus $q$, Kalimantan, Mt Bawan (RBINS). A. Habitus, dorsal view. B. Habitus, ventral view. C. Habitus, lateral view. D. Head and thorax, lateral view. E. Frons, normal view. Scale bar $=30 \mathrm{~mm}$ (D-E not to scale). 
Noteworthy, of all members of the pyrorhynchus group, the Bornean species P. intricatus (Walker, 1857) (Fig. 1) shows the greatest affinities in the pattern of the tegmina with the effusus group.

\section{Identification key to the species of the effusus group}

A Bornean species pertaining to the pyrorhynchus group, but sharing a number of characters with the species of the effusus group, P. intricatus (cf. above), is included in the key and illustrated to avoid misidentifications.

1 Head with cephalic process longer than half of tegmen (Fig. 1A, C); cephalic process slightly curved upwards, brown with bright yellow apex, without blue or green (Fig. 1D-E); ratio LPr/LF $>4$;

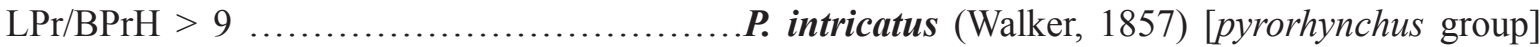

- Head with cephalic process shorter than half of tegmen (Figs 2A, C, 4A, C); cephalic process strongly curved upwards, at least partly green or blue (Figs 2D-E, 4D-E); ratio $\operatorname{LPr} / \mathrm{LF}<2.5 ; \operatorname{LPr} / \mathrm{BPrH}<7 \ldots$

2 Basal half of head yellow-brown, strongly contrasting with green or blue apical half of cephalic

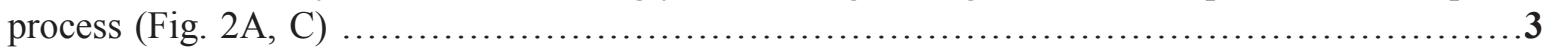

- Head unicolorous blue or green, at best slightly paler basally (Figs 4A, C, 5A, C) .................

3 Tegmina green on basal half, getting progressively more yellow on membrane, infuscate along apical margin; spots on tegmina yellow and rather large, visible on membrane (Fig. 2A) ...........

.P. effusus (Distant, 1891)

- Tegmina with basal half dark blue-green followed by a contrasting large oval yellow patch and broadly dark brown along apical margin; spots on tegmina pale yellow-white and rather small, getting indistinct on membrane (Fig. 3A)

P. gunjii (Satô \& Nagai, 1994)

4 Tegmina with transverse yellow bands on corium, the basal one complete (Fig. 4A); pro- and mesonotum concolorous (Fig. 4A); head dark olivaceous blue-green (Fig. 4A, D-E) ...P. synavei sp. nov.

- Tegmina with small round yellow spots (Fig. 5A); pronotum yellow to orange, mesonotum dark blue-green (Fig. 5A); head bright blue (often faded in collection specimens) (Fig. 5A, D-E)

.P. whiteheadi (Distant, 1889)

\section{Pyrops effusus (Distant, 1891)}

Figs 2A-E, 6-7A-C, 10A, C-F

Fulgora effusa Distant, 1891: 518, pl. XX, figs 4, 4a (Type in NHM) [described, illustrated and compared with $P$. whiteheadi (Distant, 1889)].

Fulgora viridicastanea Baker, 1925: 359, pl. 3, fig. 5, pl. 4 fig. 8 (Type in USNM) [described, illustrated and compared with $P$. whiteheadi erroneously mentioned and illustrated as "Fulgora effusa"]. Synonymized under $P$. effusus by Nagai \& Porion (2004).

Fulgora effusa - Schmidt 1905: 349 [comparative note with other species]; 354 [mention of a specimen in the Stettiner Museum]. - Lallemand 1963: 88 [synonymized under whiteheadi (erroneous)]. Liang 1998: 45 [listed as junior synonym of $P$. whiteheadi (erroneous)].

Pyrops effusa (sic!) - Schmidt 1926: 47 [transferred to Pyrops; compared with P. peltzeri Schmidt, 1926, the latter synonymized under P. pythicus (Distant, 1891) by Lallemand (1963)]. — Nagai \& Porion 1996: 26 [transferred back to Pyrops; catalogued as junior synonym of $P$. whiteheadi (erroneous)], pl. 11, fig. 163 [type of $P$. effusus illustrated under the name of $P$. whiteheadi]. - Nagai \& Porion 2004: 6 [removal from synonymy with $P$. whiteheadi; notes on morphology; senior synonym of $P$. viridicastaneus and distribution], pl. 1, figs 2, 4 [illustrated from 2 localities]. 
Laternaria effusa - Metcalf 1947: 196 [transferred to Laternaria; catalogued]. — Liang 1998: 45 [listed as junior synonym of $P$. whiteheadi (erroneous)].

Laternaria viridicastanea - Metcalf 1947: 207 [transferred to Laternaria; catalogued]. — Liang 1998: 45 [listed as junior synonym of $P$. whiteheadi (erroneous)].

Fulgora viridicastanea - Lallemand 1963: 88 [synonymized under P. whiteheadi (erroneous) and compared with $P$. whiteheadi and $P$. effusus; transferred back to Fulgora (erroneous)]. - Liang 1998: 45 [listed as junior synonym of $P$. whiteheadi (erroneous)].

Fulgora whiteheadi - Lallemand 1963: 88, pl. X, figs 11-13 [keyed, comments illustration of male genitalia (based on misidentified specimens of $P$. effusus)].

Fulgora whiteheadi viridicastanea - Satô \& Nagai 1994 [considered as a subspecies of $P$. whiteheadi (erroneous) and compared with "Fulgora whiteheadi gunjii"].

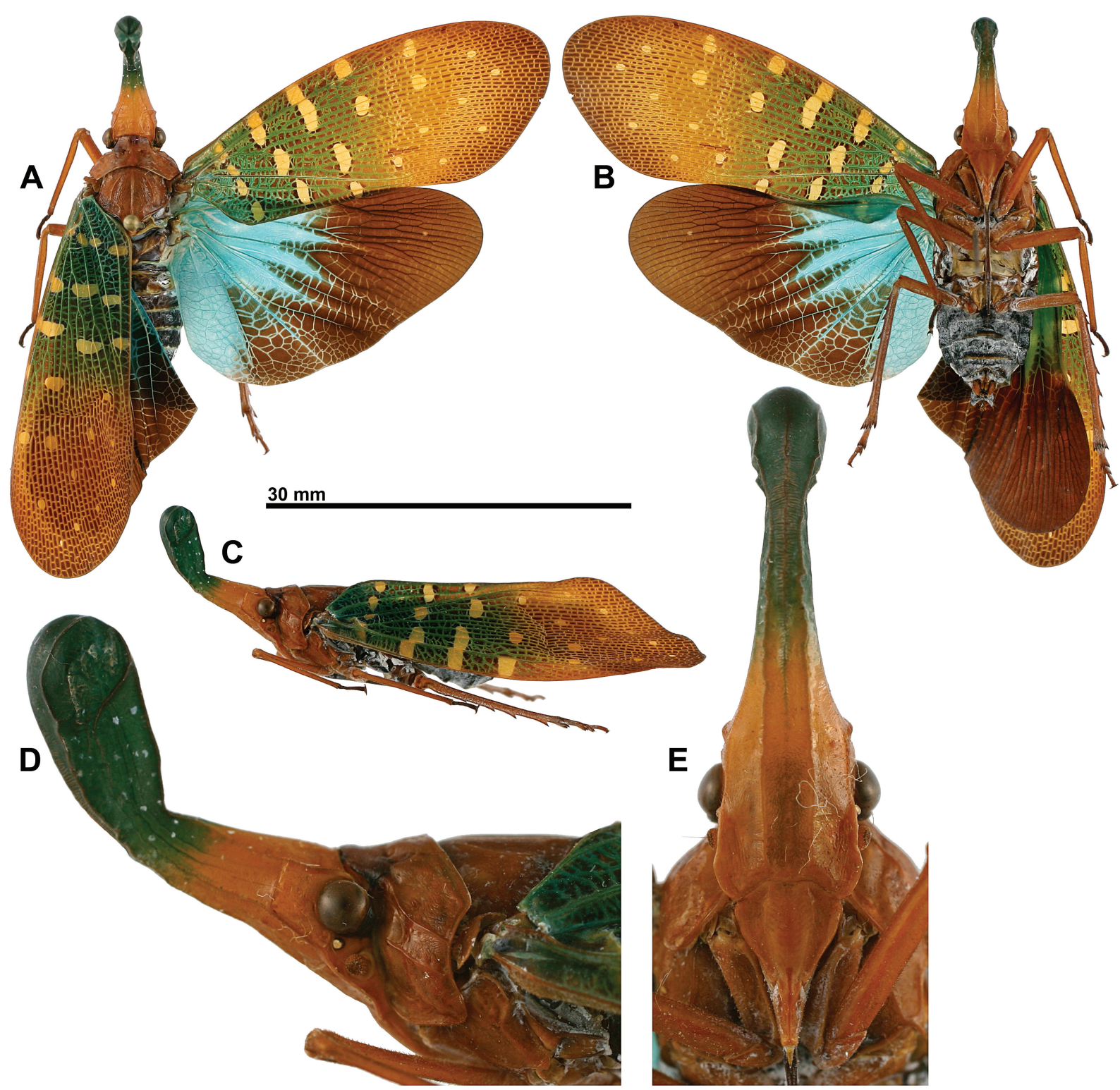

Fig. 2. Pyrops effusus + , Kalimantan, Batulicin (RBINS). A. Habitus, dorsal view. B. Habitus, ventral view. C. Habitus, lateral view. D. Head and thorax, lateral view. E. Frons, normal view. Scale bar $=30$ $\mathrm{mm}$ (D-E not to scale). 
Pyrops viridicastanea - Nagai \& Porion 1996: 26 [transferred back to Pyrops; catalogued as junior synonym of $P$. whiteheadi (erroneous)]. - Nagai \& Porion 2004: 6 [synonymized under $P$. effusus, notes].

Pyrops whiteheadi (Distant, 1889) - Nagai \& Porion 1996, pl. 11, fig. 163 [illustration of the type of $P$. effusus (Distant, 1891)].

non Fulgora effusa - Baker 1925: 359, pl. 3, fig. 4, pl. 4, fig. 7 [described, illustrated (misidentification of Pyrops whiteheadi)].

\section{Diagnosis}

In addition to the characters defining the effusus group, the species can be recognized by: (1) head yellow-brown with apical half of cephalic process blue (often faded to greenish in collection specimens) (Fig. 2D-E); (2) pro- and mesonotum yellow-brown (Fig. 2A); (3) tegmina green with yellow spots also beyond nodal line; on basal half, spots tranverse and sometimes coalescent (Fig. 2A); (4) tegmina without large pale yellow patch at nodal line and apical margin slightly infuscate (Fig. 2A).

\section{Material examined}

Type material

INDONESIA: Holotype of Fulgora effusa (examined on photographs), ô: [Borneo] [effusa Dist.] [Distant Coll. 1911-383.] (BMNH).

INDONESIA: Holotype of Fulgora viridicastanea (examined on photographs, Fig. 10C-F), $q$ : [Banjermassin, Borneo] [Fulgora viridicastanea Baker] (USNM).

\section{Additional material}

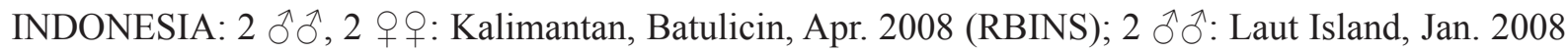
(RBINS); 1 \&, Laut Island, Jun. 2004 (RBINS); 1 §ै, E-Borneo, Midden, 10 Oct. 1925, H.C. Siebers

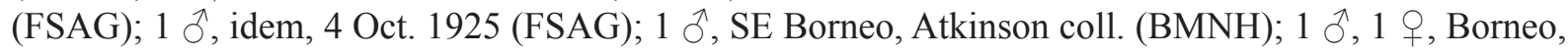
1909 (BMNH); 1 , , North Borneo (BMNH).

\section{Examined on photograph}

INDONESIA: 1 specimen (Fig. 10A), Kalimantan, Wehea Protected Forest, 25 Sep. 2010, Kara Norby.

\section{Measurements and ratios}

TL: $\widehat{\partial}(\mathrm{n}=4): 35.1 \mathrm{~mm}(34.3-36.0)$; + $(\mathrm{n}=2): 40.2 \mathrm{~mm}(40.0-40.5)$; TL+process: $\widehat{\jmath}(\mathrm{n}=4): 42.5 \mathrm{~mm}$ $(41.0-43.2) ;$ ㅇ $(\mathrm{n}=2): 46.7 \mathrm{~mm}(46.4-47.0) ; \mathrm{LTg} / \mathrm{BTg}=2.33 ; \mathrm{BF} / \mathrm{BPrH}=3.0 ; \mathrm{LPr} / \mathrm{LF}=2.18 ; \mathrm{LPr} /$ $\mathrm{BPrH}=6.92$.

\section{Male genitalia}

Pygofer and anal tube dark brown; gonostyli brown, paler dorsally and dark brown basoventrally. Pygofer higher than long, with posterior margin sinuate in lateral view (Fig. 7A). Anal tube slightly elongate, 1.20 times as long as broad, broader at 2/3 of total length (Fig. 7A-B); lateral margins slightly sinuate (Fig. 7B) and apical margin strongly notched in dorsal view (Fig. 7B). Gonostyli (Fig. 7A) elongate with posterior margin broadly rounded (Fig. 7A, C).

\section{Distribution}

Known from Borneo, South Kalimantan and southern East Kalimantan, and Laut Island (Fig. 6). 
CONSTANT C., Fulgoridae: Pyrops effusus species group (Hemiptera)

\section{Biology}

No host tree has been identified for this species, for which records are available for the months January, April, June, September and October.

\section{Note}

Nagai \& Porion (2004) mentioned the existence of 2 types of specimens showing (1) strongly and (2) weakly contrasted colour of the tegmina and illustrated both (Nagai \& Porion 2004: figs 2, 4). They mentioned the strongly contrasted ones from Laut Island and Kutai, and the weakly contrasted ones from Loksado (confirmed by the examination of the specimens in MHNL collections by H. Labrique, pers. comm. Mar. 2015). Since then strongly contrasted specimens were found in several locations on Borneo and weakly contrasted ones on Laut Island, which seems to confirm that they occur together. The occurrence of pale and dark forms in the same species was already known from other species of Pyrops, e.g., P. sultanus (Adams \& White, 1847) (see also Nagai \& Porion 1996: figs 189, 191), and P. lathburii (Kirby, 1818) (see also Nagai \& Porion 1996: figs 194, 196, 198).

Pyrops gunjii (Satô \& Nagai, 1994) stat. nov.

Figs 3A-E, 6, 8A-C, 10B

Fulgora whiteheadi gunjii Satô \& Nagai 1994: 308, figs 2, 9 (Type in EUM) [described, illustrated and compared with $P$. whiteheadi and $P$. effusus, the latter mentioned as " $F$. whiteheadi viridicastanea"].

Pyrops whiteheadi gunjii - Nagai \& Porion, 1996: 26, pl. 17, fig. 210 [transferred to Pyrops; listed, illustrated]. - Liang 1998: 45 [listed, erroneous mention of new combination already proposed by Nagai \& Porion (1996)].

\section{Diagnosis}

In addition to the characters defining the effusus group, the species can be recognized by: (1) head yellow-brown with apical half of cephalic process blue (often faded to green in collection specimens) (Fig. 3D-E); (2) pro- and mesonotum yellow-brown (Fig. 3A); (3) tegmina dark blue-green on corium, with small yellow-white spots; on basal half, spots slightly tranverse and rarely coalescent, spots barely distinct on membrane (Fig. 3A); (4) tegmina with large pale yellow-brown patch at nodal line and apical margin broadly infuscate (Fig. 3A).

\section{Material examined}

Type material

Holotype $\widehat{\delta}$ (examined on photographs): [Embalut, E. Kalimantan, INDONESIA, Sep. 22. 1988] [Holotype Fulgora whiteheadi gunjii, M. Sato \& S. Nagai, 1994] (EUM).

Note: Satô \& Nagai (1994) stated that the type was collected by S. Okada and suggested that the type location was probably "Ambalut, Samarinda" rather than "Embalut".

Additional material

INDONESIA: $2 \precsim \widehat{\jmath}$, E Kalimantan, Samarinda, Mt Beratus, Aug. 2006, S. Jakl (RBINS); 1 , , no data (RMNH).

\section{Examined on photographs}

INDONESIA: 1 specimen (Fig. 10B), East Kalimantan, 0³2’4.70’S 117²7’46.73’E, 3 Jul. 2011, Martin Hauskrecht; 1 specimen, East Kalimantan, Kutai National Park, 7 Jan. 2009, Martin Dancak; 1 specimen, East Kalimantan, Kutai National Park, 26 Sept. 2009, "Sophie \& Dale”; 1 specimen, East 
Kalimantan, Kutai National Park, 28 Jan. 2010, Darwyn Moffatt-Mallett; 1 specimen, East Kalimantan, Penajam Paser Utara, 17 Mar. 2010, "Emjanda”.

\section{Measurements and ratios}

TL: $\widehat{\partial}(\mathrm{n}=2): 35.1 \mathrm{~mm}(34.5-35.6) ;$; $(\mathrm{n}=1): 38.6 \mathrm{~mm}$; TL+process: $\widehat{\partial}(\mathrm{n}=2): 39.7 \mathrm{~mm}(39.0-40.3)$; ㅇ $(\mathrm{n}=1): 44.0 \mathrm{~mm} ; \mathrm{LTg} / \mathrm{BTg}=2.53 ; \mathrm{BF} / \mathrm{BPrH}=3.0 ; \mathrm{LPr} / \mathrm{LF}=1.88 ; \mathrm{LPr} / \mathrm{BPrH}=6.97$.

\section{Male genitalia}

Dark brown with gonostyli paler dorsally. Pygofer higher than long, with posterior margin sinuate in lateral view (Fig. 8A). Anal tube slightly elongate, 1.10 times as long as broad, broader at $4 / 5$ of total length (Fig. 8A-B); lateral margins slightly sinuate (Fig. 8B) and apical margin strongly notched in dorsal view (Fig. 8B). Gonostyli (Fig. 8A) elongate with posterior margin roundly pointed (Fig. 8A, C).

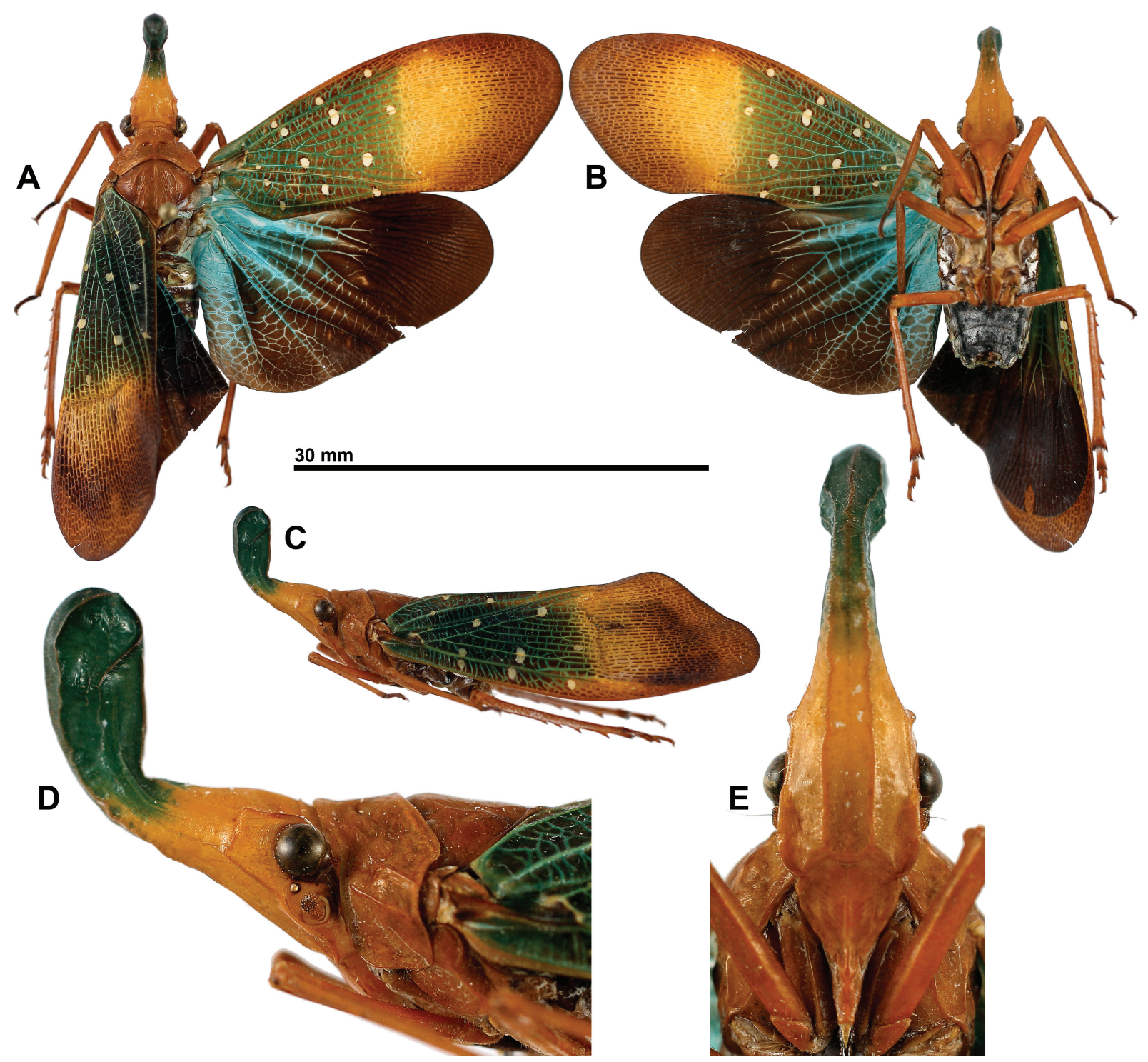

Fig. 3. Pyrops gunjii $\widehat{\partial}$, E Kalimantan, Samarinda, Mt Beratus (RBINS). A. Habitus, dorsal view. B. Habitus, ventral view. C. Habitus, lateral view. D. Head and thorax, lateral view. E. Frons, normal view. Scale bar $=30 \mathrm{~mm}$ (D-E not to scale). 
CONSTANT C., Fulgoridae: Pyrops effusus species group (Hemiptera)

\section{Distribution}

Known from Borneo, south-eastern East Kalimantan (Fig. 6).

\section{Biology}

No host tree has been identified for this species, for which records are available from the months of January, March, July, August and September.

\section{Remarks}

The species epithet refers to the Japanese entomologist Mr Yoshiaki Gunji.

$$
\begin{gathered}
\text { Pyrops synavei sp. nov. } \\
\text { urn:1sid:zoobank.org:act:B502AF69-AEC2-4245-B440-57F75BF8559E }
\end{gathered}
$$

Figs 4A-E, 6, 11A-D

\section{Diagnosis}

In addition to the characters defining the effusus group, the species can be recognized by: (1) head entirely dark olivaceous blue-green (Fig. 4D-E); (2) pro- and mesonotum bluish-brown (Fig. 4A); (3) tegmina green with yellow spots also beyond nodal line; on corium, basal row of spots fused in a transverse band, next rows fused into incomplete tranverse bands (Fig. 4A); (4) tegmina without large pale yellow patch at nodal line and apical margin very slightly infuscate (Fig. 4A).

\section{Etymology}

The species epithet refers to the late Belgian hemipterist Henry Synave (1921-1981). He was the author of numerous publications on Auchenorrhyncha, and of all drawings of Lallemand's revisions of the Fulgoridae $(1959,1963)$.

\section{Material examined}

Type material

INDONESIA: Holotype, : [N.O. Borneo, S. Peleben, 7.u.8.1935, Baron Plessen] [R.I.Sc.N.B., I.G. 23.860] [H. Synave det., 1968, Laternaria intricata Walk.] (RBINS). Coordinates of S Peleben: $2^{\circ} 47^{\prime} \mathrm{N}$ $116^{\circ} 35^{\prime} \mathrm{E}$.

\section{Examined on photographs}

1 specimen (Fig. 11A-B): Kalimantan, Long Alango, Lalut Birai Sacred Forest, 2 Sep. 2011, Joost Woltering; 1 specimen (Fig. 11C-D): Kalimantan, Lalut Birai Forest, 13 Mar. 2009, Dave Forney. Coordinates of Lalut Birai Forest: $3^{\circ} 12^{\prime} \mathrm{N} 115^{\circ} 30^{\prime} \mathrm{E}$.

\section{Measurements and ratios}

TL: + $(\mathrm{n}=1): 40.9 \mathrm{~mm}$; TL+process: $\&(\mathrm{n}=1): 47.7 \mathrm{~mm} ; \mathrm{LTg} / \mathrm{BTg}=2.50 ; \mathrm{BF} / \mathrm{BPrH}=2.78 ; \mathrm{LPr} / \mathrm{LF}$ $=2.48 ; \mathrm{LPr} / \mathrm{BPrH}=6.78$.

\section{Description}

HEAD. Dark olivaceous blue-green progressively turning more brownish basally (Fig. 4A, D-E). Cephalic process slightly longer than frons and clypeus together in normal view of frons (Fig. 4E), strongly curved anterodorsad and bent in middle dorsally (Fig. 4D); apical half slightly dilated and rounded apically in lateral view (Fig. 4D), with sides parallel in anteroventral view (Fig. 4E). Two longitudinal carinae on frons extending on sides of cephalic process up to apex, undulated. Median, ventral undulated 
carina on apical half of cephalic process (Fig. 4E). Frons subquadrate (Fig. 4E). Clypeus elongate with smooth median carina. Labium brown-black, slightly surpassing posterior trochanter. Antennae brown.

Thorax (Fig. 4A, D). Olivaceous brown, pro- and mesonotum greener in middle. Pronotum irregularly wrinkled with smooth longitudinal carina and 2 strongly impressed points on anterior half of disc (Fig. 4A), dorsolateral and lateral carinae well marked (Fig. 4A, D). Mesonotum with disc wrinkled and sides smooth; 3 smooth longitudinal carinae not reaching anterior margin, median one reaching base of scutellum posteriorly; slight impression along posterior margin at base of scutellum; scutellum slightly elevated apically. Tegulae olivaceous brown.

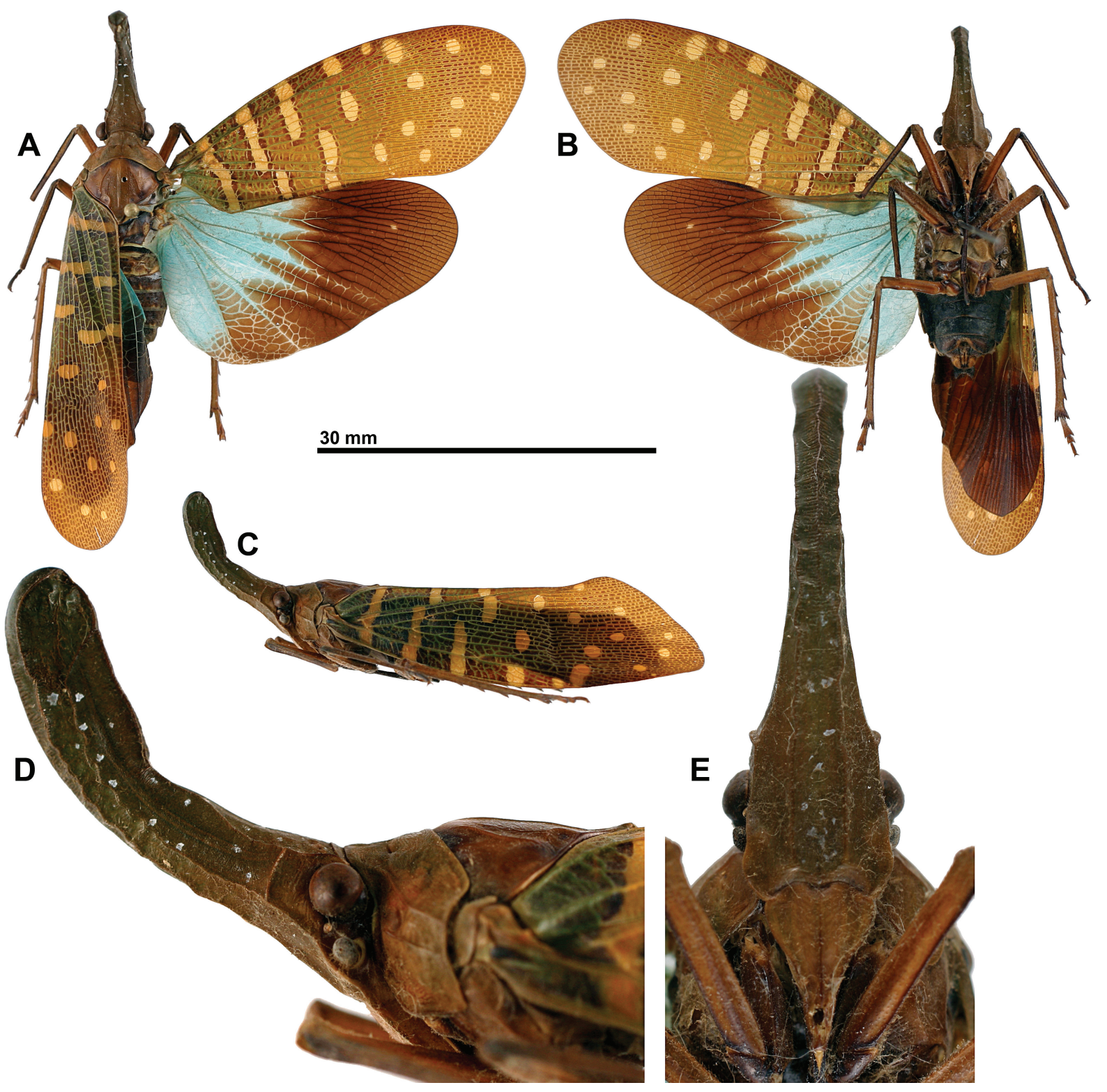

Fig. 4. Pyrops synavei sp. nov. ㅇ, holotype (RBINS). A. Habitus, dorsal view. B. Habitus, ventral view. C. Habitus, lateral view. D. Head and thorax, lateral view. E. Frons, normal view. Scale bar $=30 \mathrm{~mm}$ (D-E not to scale). 
TEGmina (Fig. 4A). Dark green-brown with veins green turning to brown near apical margin. 3 more or less interrupted transverse yellow bands on corium; more basal one complete; median one sometimes cut at costal vein or/and claval suture; third band in 2-3 parts often not aligned. Row of 3 more or less oval yellow spots on nodal line. Yellow markings on corium and nodal line bordered with dark brown. 8-9 round yellow spots on membrane. Apical margin oblique with angles broadly rounded; costal margin slightly rounded.

HIND wings (Fig. 4A). Bright blue with apex and sutural margin largely brown-black; brown black extending into blue along main veins; cross-veinlets blue in brown-black area on baso-sutural half. Hind wings slightly broader than tegmina.

Legs (Fig. 4A-B). Dark olivaceous brown. Metatibiae with 6 lateral and 7 apical spines.

ABDomen (Fig. 4A-B). Tergites brown-black; sternites black; genital segments tinged with yellowbrown.

\section{Distribution}

Known from Borneo, North Kalimantan (see map Fig. 6).

\section{Biology}

No host tree has been identified for this species for which records are available from the months of March, July - August and September.

Pyrops whiteheadi (Distant, 1889)

Figs 5A-E, 6, 9A-C, 12A-E

Fulgora whiteheadi Distant 1889: 422 (Type in NHM) [described and compared to P. delesserti (GuérinMéneville, 1840)].

Fulgora whiteheadi - Distant 1891: 518 [compared to P. effusus]. — Lallemand 1963: 88 [considered as senior synonym of $P$. effusus and $P$. viridicastaneus (erroneous); described, keyed; interpretation of the species mixing P. effusus and P. whiteheadi]. — Satô \& Nagai 1994: 308 [compared with $P$. gunjii].

Fulgora effusa-Baker 1925: 359 [comparison between P. effusus and P. whiteheadi based on specimens of $P$. whiteheadi erroneously identified as $P$. effusus].

Laternaria whiteheadi - Metcalf 1947 [transferred to Laternaria; catalogued].

Pyrops whiteheadi - Nagai \& Porion 1996: 26 [transferred to Pyrops; listed], pl. 11, fig. 160 [type illustrated]. — Liang 1998: 45 [listed]. — Nagai \& Porion 2004: 6 [comparison with P. effusus], pl. 1, fig. 6 [illustration of habitus].

non Fulgora whiteheadi - Lallemand 1963: pl. X, figs 11-13 [illustration of the genitalia of P. effusus erroneously identified as $P$. whiteheadi].

non Pyrops whiteheadi - Nagai \& Porion 1996: pl. 17, fig. 213 [illustration of a specimen of P. effusus erroneously identified as $P$. whiteheadi].

\section{Diagnosis}

In addition to the characters defining the effusus group, the species can be recognized by: (1) head entirely blue (often faded to greenish in collection specimens) (Fig. 5D-E); (2) pronotum yellow-brown, mesonotum blue-brown (Fig. 5A); (3) tegmina green with small yellow spots also beyond nodal line; 
spots rounded and not coalescent (Fig. 5A); (4) tegmina without large pale yellow patch at nodal line and with apical margin slightly infuscate (Fig. 5A).

\section{Material examined}

Type material

MALAYSIA: Lectotype: $\hat{\sigma}$, here designated to provide a reference standard for the species (examined on photographs): East Malaysia, [Kina Balu (Whitehead)] [Whiteheadi Dist.] [Distant Coll. 1911— 383.] [Type] (BMNH).

MALAYSIA: Paralectotypes: $2 \hat{\jmath}, 2$ 우우 (examined on photographs): East Malaysia, [Kina Balu (Whitehead)] [Whiteheadi Dist.] [Distant Coll. 1911-383.] (BMNH).

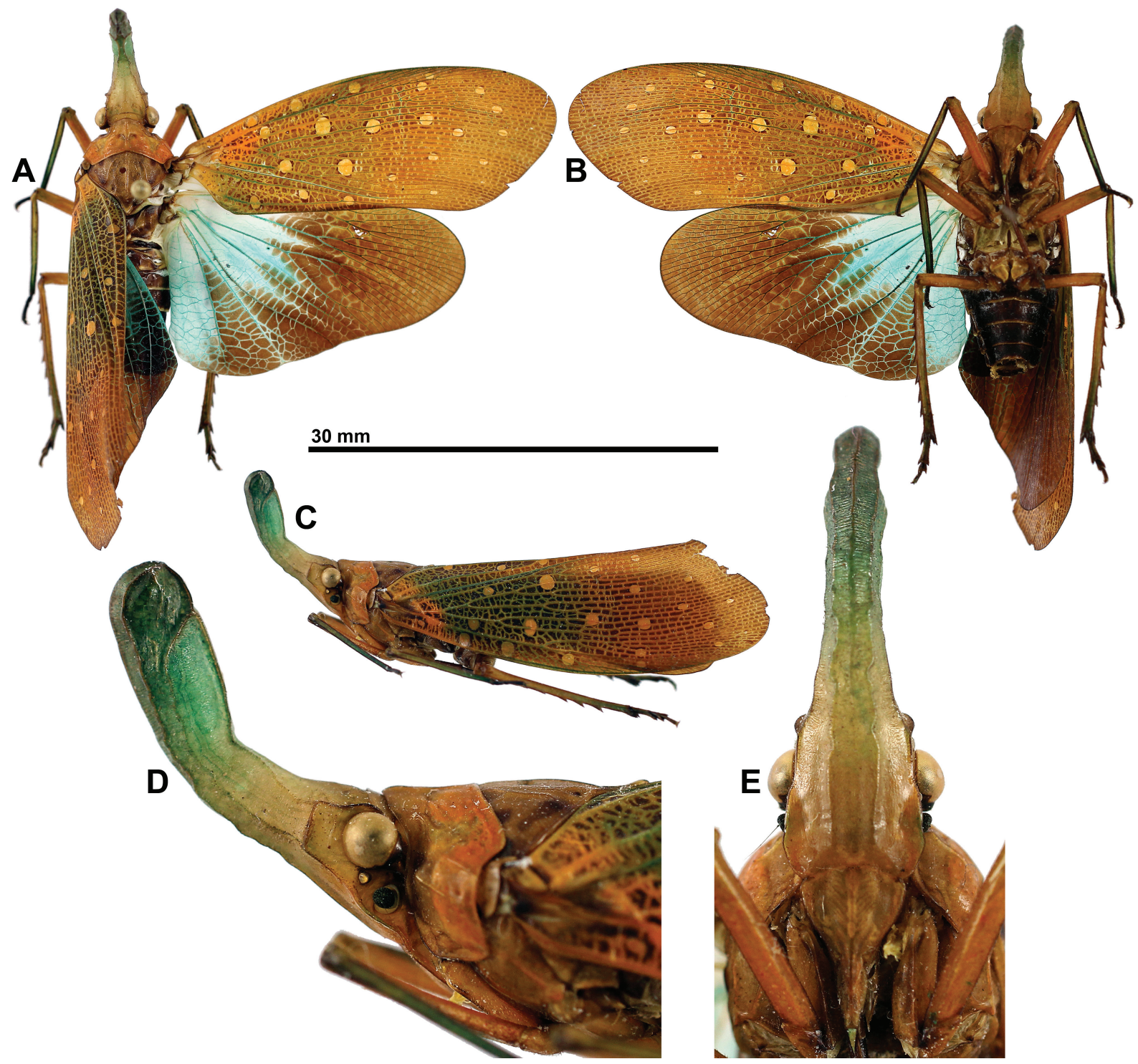

Fig. 5. Pyrops whiteheadi ${ }^{\lambda}$, Sabah, Danum Valley (RMNH). A. Habitus, dorsal view. B. Habitus, ventral view. C. Habitus, lateral view. D. Head and thorax, lateral view. E. Frons, normal view. Scale bar $=30 \mathrm{~mm}$ (D-E not to scale). 


\section{Additional material}

MALAYSIA: 1 đ̊, Sabah, Kinabalu National Park, Poring Hot Spring, 21 Apr. 1999, T. Trilar (RBINS);

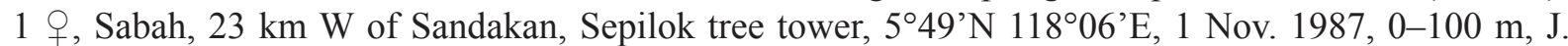

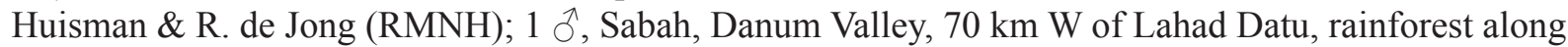
narrow stream, at light, next to bridge Nature Trail, 50 m, 1 Dec. 1989, M.J. \& J.P. Duffels (RMNH).

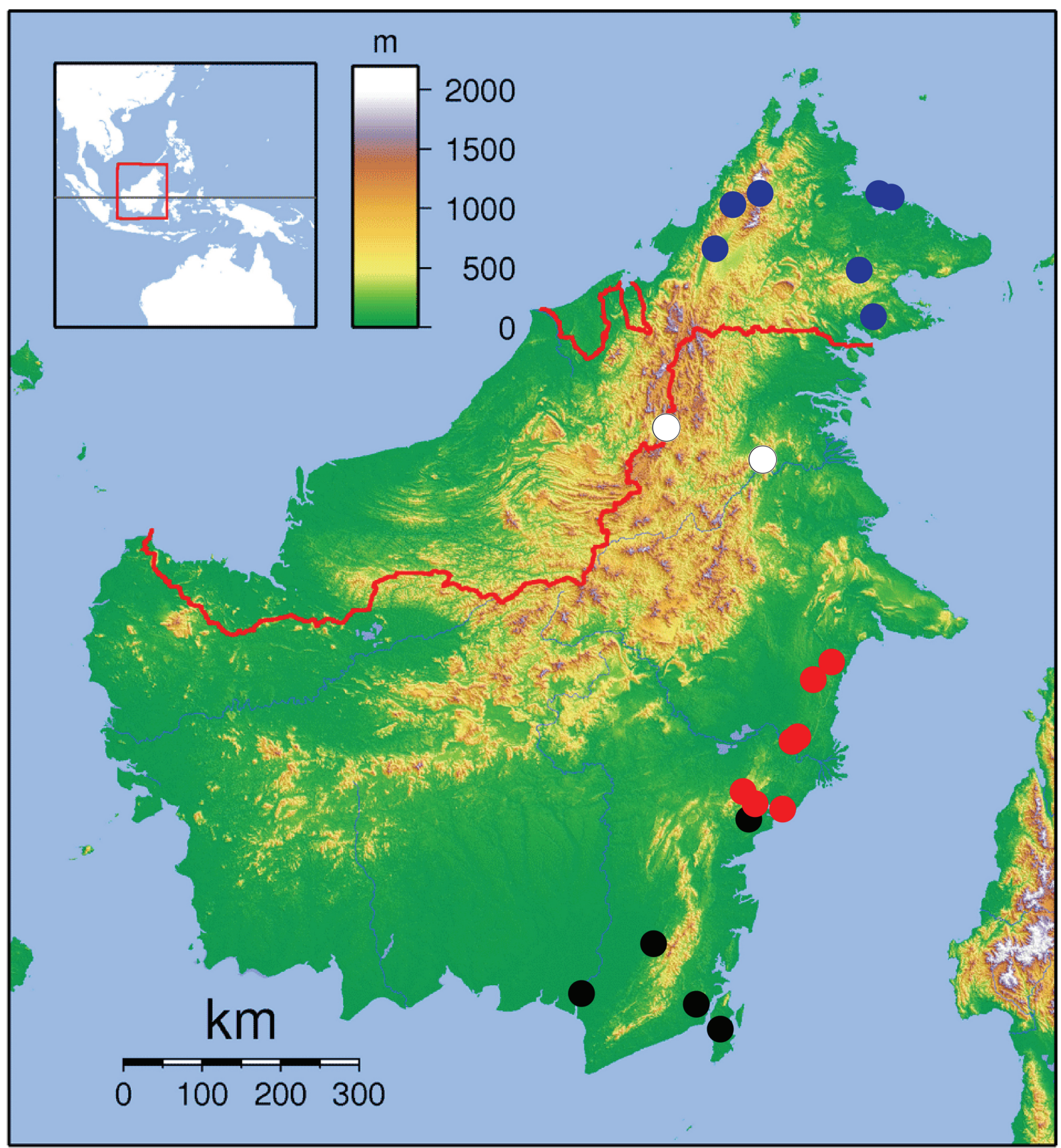

Pyrops effusus (Distant, 1891)

Pyrops gunjii (Satô \& Nagai, 1994)

Pyrops synavei sp. nov.

Pyrops whiteheadi (Distant, 1889)

Fig. 6. Pyrops effusus group, distribution map. 


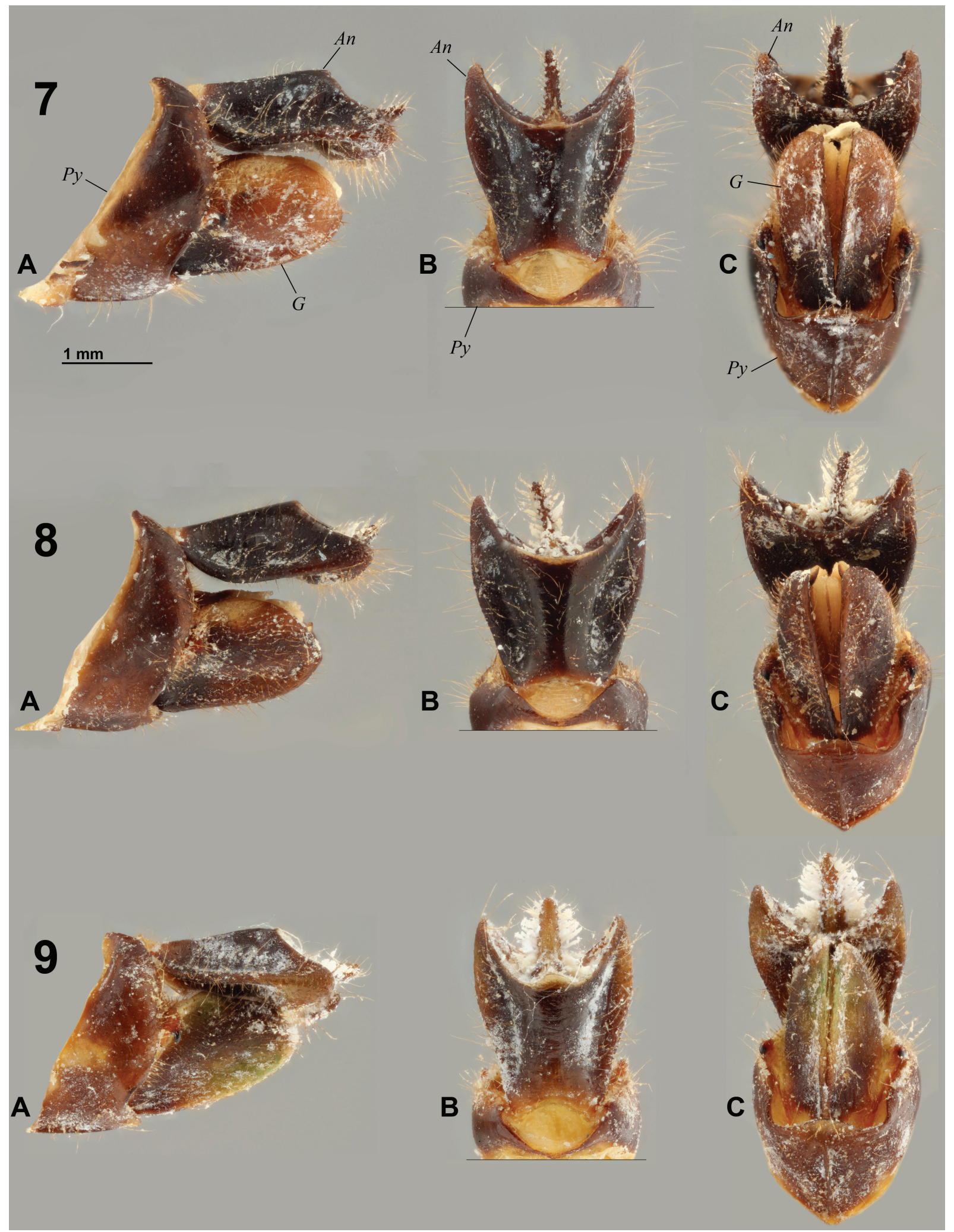

Figs 7-9. Pyrops effusus group, ô genitalia. 7. Pyrops effusus. 8. Pyrops gunjii. 9. Pyrops whiteheadi. A. Lateral view. B. Dorsal view. C. Posteroventral view. $A n=$ anal tube, $G=$ gonostylus, $P y=$ pygofer. Scale bar $=1 \mathrm{~mm}$. Photographs by J. Brecko. 
CONSTANT C., Fulgoridae: Pyrops effusus species group (Hemiptera)

\section{Note}

One specimen labelled: Selangor, Banting, 2 Oct. [19]89, Ismail \& Ruslan in the collections of BMNH, has been examined on photograph. The location is in West Malaysia and the specimen is assumed to be mislabelled.
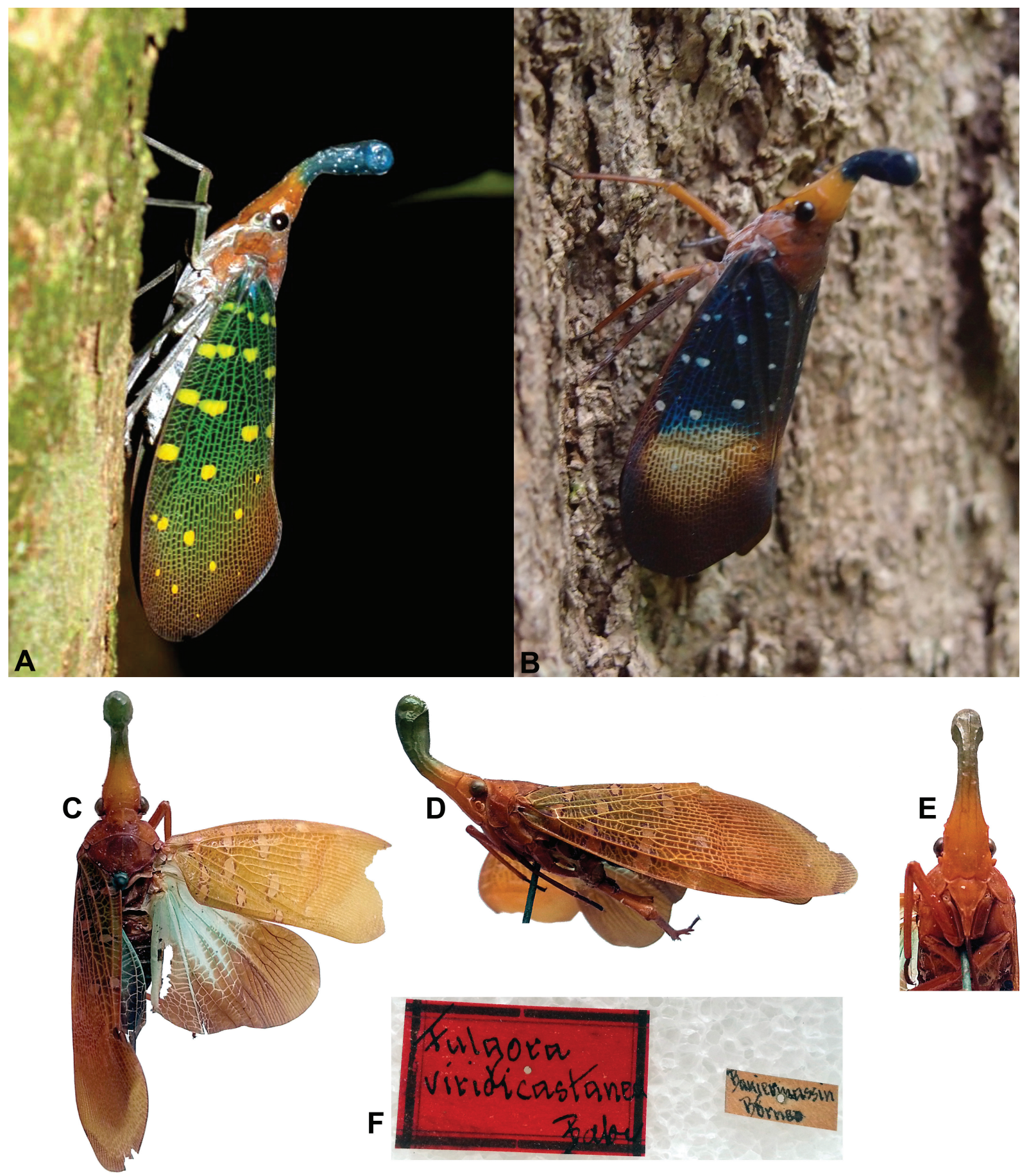

Fig. 10. - A. Pyrops effusus, in natura, Borneo, Kalimantan, Wehea Protected Forest, 25 Sep. 2010, K. Norby. - B. Pyrops gunjii, in natura, Borneo, East Kalimantan, 0³2’4.70”S 117'27’46.73”'E, 3 Jul. 2011, M. Hauskrecht. - C-F. Fulgora viridicastanea, holotype (Photographs A. Kennedy). C. Dorsal view. D. Left lateral view. E. Head, normal view of frons. F. Labels. 


\section{Examined on photographs}

EAST MALAYSIA: 1 specimen (Fig. 12A-B), Sabah, Danum Valley, 4 Jul. 2013, Anton Sorokin; 1 specimen, idem, 13 Jun. 2013; 1 specimen, idem, 3 Oct. 2010, Hok Ping Guek; 1 specimen, idem, 4 Oct.

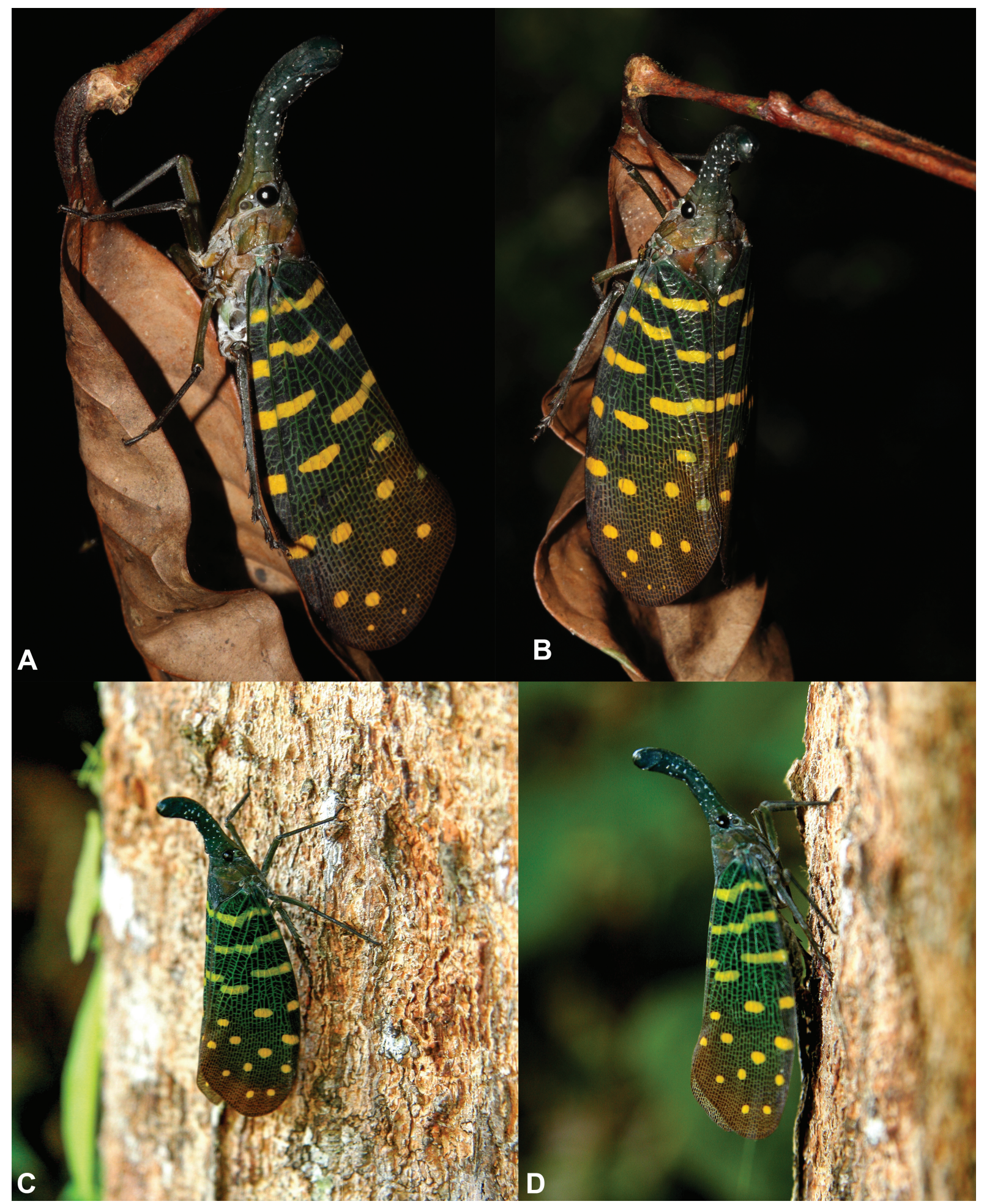

Fig. 11. Pyrops synavei sp. nov. in natura. A-B. Borneo, Kalimantan, Long Alango, Lalut Birai Sacred Forest, 2 Sep. 2011, J. Woltering. C-D. Borneo, Kalimantan, Lalut Birai Forest, 13 Mar. 2009, D. Forney. 
2013; 1 specimen, idem, 18 Aug. 2008, Thomas Bridle; 2 specimens, idem, 27 Sept. 2009, Tim Moss; 1 specimen, idem, 3 Jun. 2007, Karin Saner; 1 specimen, idem, Aug. 2004, Dirk Mezger; 1 specimen (Fig. 12C), Sabah, Danum Valley, 15 Dec. 2008, Ch'ien C. Lee; 1 specimen (Fig. 12D), Sabah, Lower Kinabatangan River, 9 Aug. 2012, Nicola Messina; 1 specimen (Fig. 12E), Sabah, Sepilok, 6 Jun. 2013, Ch'ien C. Lee; 2 specimens, Keningau, 24 Sep. 2011, Khairin Saili; 2 specimens, Kinabatangan, 14 Feb. 2008, Christophe Maerten; 1 specimen, idem, 21 Jan. 2008, Andrea Ferrari; 1 specimen, idem, 17 Oct. 2009, "Pietra \& Paoli"; 1 specimen, idem, 24 May 2010, Frank Joas; 1 specimen, Kinabatangan, Sukau, 12 Aug. 2011, J.M. Gayman; 1 specimen, Sandakan, 27 Mar. 2013, Gavin Golden; 1 specimen, Sandakan, Sukau, 14 Aug. 2009, Samuel Tan; 1 specimen, Taman Bukit Tawau, 17 Aug. 2012, Subki Abdul Hadi; 1 specimen, Sepilok, 1 Aug. 2010, J.P. Lawrence; 1 specimen, idem, 15 Aug. 2011.

\section{Measurements and ratios}

TL: $\hat{\jmath}(\mathrm{n}=2): 34.8 \mathrm{~mm}(34.3-35.2)$; + $(\mathrm{n}=1): 38.0 \mathrm{~mm}$; TL+process: $\widehat{\jmath}(\mathrm{n}=2): 39.8 \mathrm{~mm}(38.7-40.9)$; ㅇ $(\mathrm{n}=1): 42.2 \mathrm{~mm} ; \mathrm{LTg} / \mathrm{BTg}=2.73 ; \mathrm{BF} / \mathrm{BPrH}=3.0 ; \mathrm{LPr} / \mathrm{LF}=2.5 ; \mathrm{LPr} / \mathrm{BPrH}=5.4$.

\section{Male genitalia}

Brown with gonostyli paler dorsally and ventrally. Pygofer higher than long, with posterior margin sinuate in lateral view (Fig. 9A). Anal tube slightly elongate, 1.25 times as long as broad, broader at 4/5 of total length (Fig. 9A-B); lateral margins very slightly sinuate (Fig. 9B) and apical margin strongly notched in dorsal view (Fig. 9B). Gonostyli (Fig. 9A) elongate with posterior margin rounded, slightly narrowing (Fig. 9A, C).

\section{Distribution}

Borneo, known from Sabah (Fig. 6).

\section{Biology}

No host tree has been identified for this species, for which records are available from all months of the years, with a higher number of records (8/26) in August. However, we do not conclude that the species is more abundant in August; as most data are from photographs taken by tourists, it is possible that the higher amount of available data is biased by the fact that August is a holiday period in many countries.

\section{Notes on trophobiosis with Pyrops whiteheadi and P. intricatus}

Trophobiosis with ants commonly occurs in Hemiptera, and ant-attendance involving Fulgoromorpha was reviewed by Bourgoin (1997) who recorded the phenomenon in 5 families of Fulgoromorpha (Cixiidae, Delphacidae, Issidae, Hypochthonellidae and Tettigometridae). He recognized 4 main types of ant-attendance, from opportunistic attendance by ants to long term attendance where ants collect honeydew directly from the anal opening of the planthopper. At the time, no interaction was known to involve Fulgoridae.

Trophobiotic interactions between Fulgoridae and other animals attracted by the droplets of honeydew produced by the lanternflies were only recently reported by (1) Roth \& Naskrecki (2001), involving Neotropical species of the genera Copidocephala Stal, 1869 and Enchophora Spinola, 1839, with Blattodea; (2) Naskrecki \& Nishida (2007), involving Neotropical species of the genera Copidocephala, Enchophora and Phrictus Spinola, 1839, with Blattodea, Lepidoptera and gastropods; (3) Kemal \& Koçak (2012) between Pyrops candelaria (Linnaeus, 1758) and the gecko Hemidactylus platyurus (Schneider, 1792) (Squamata: Gekkonidae) in Thailand.

Interactions between geckos ( 5 species belonging to 3 different genera) and another family of Fulgoroidea, Flatidae, in Madagascar, were previously reported and analyzed by Fölling et al. (2001). 


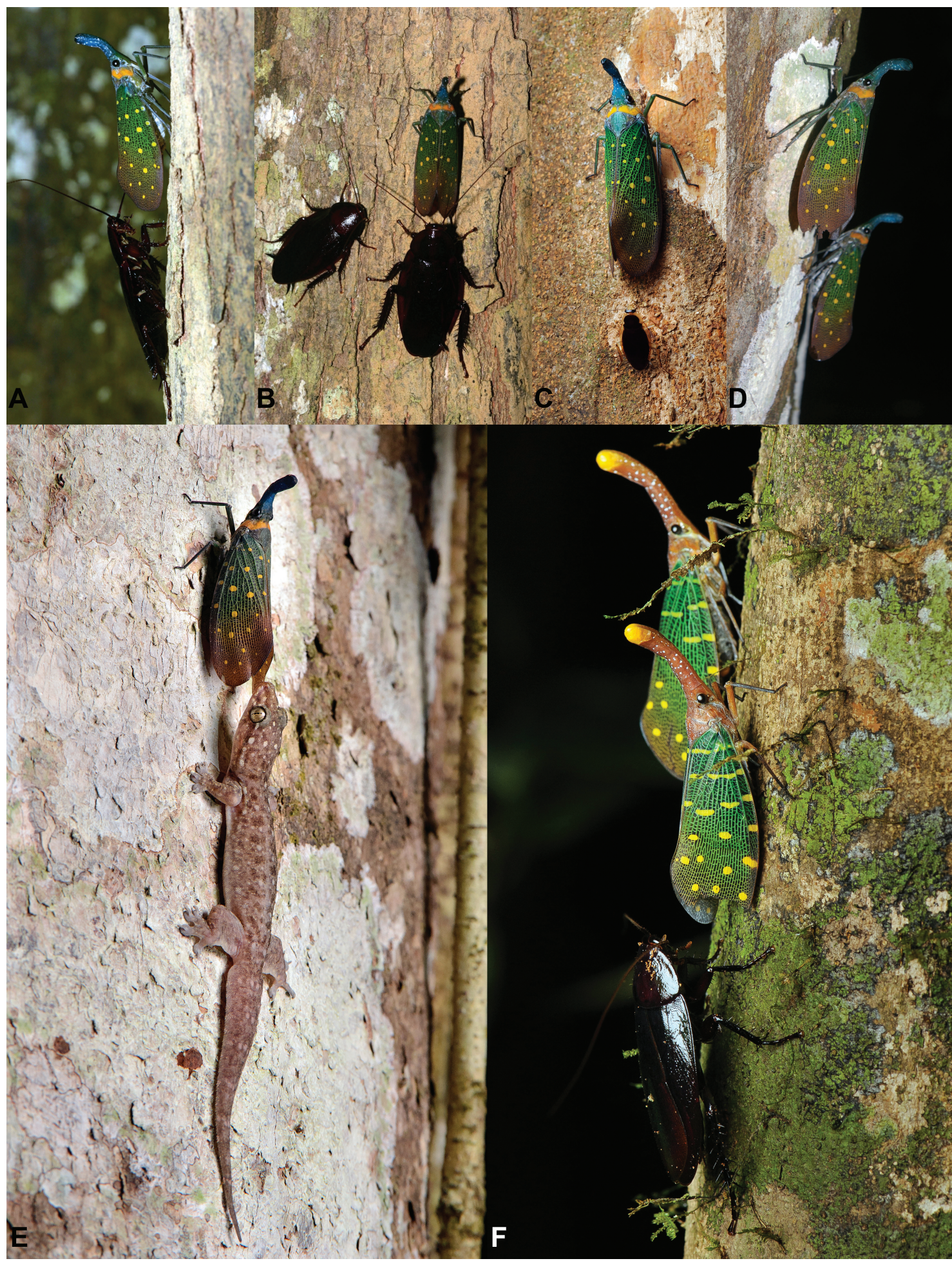

Fig. 12. Pyrops whiteheadi and P. intricatus, in natura, trophobiosis. - A-E. P. whiteheadi. A-B. Tended by cockroaches (Blattodea, Dorylaea, probably D. magna (Schelford, 1909)), Sabah, Danum Valley, 4 Jul. 2013, A. Sorokin. C. Tended by small cockroach (Blattodea, Pseudophyllodromiinae), Sabah, Danum Valley, 15 Dec. 2008, C.C. Lee. D. Sabah, Lower Kinabatangan River, 9 Aug. 2012, N. Messina. E. Tended by an adult gecko, Gehyra mutilata (Wiegmann, 1835) (Squamata: Gekkonidae), Sabah, Sepilok, 6 Jun. 2013, C.C. Lee. - F. P. intricatus tended by cockroach (Blattodea, Dorylaea sp.), Sarawak, Mulu National Park, 15 Oct. 2009, C.C. Lee. 
Similar interactions have been observed and documented between Pyrops whiteheadi and two species of Blattodea in Sabah, Danum Valley: one species of the subfamily Pseudophyllodromiinae (C.C. Lee pers. comm., Fig. 12C) and one species of the genus Dorylaea (A. Sorokin pers. comm., Fig. 12A-B), possibly D. magna (Schelford, 1909) (identifications of the Blattodea by G. Beccaloni, Dec. 2014).

Interactions between one species of gecko (Squamata: Gekkonidae), Gehyra mutilata (Wiegmann, 1835) (identification by O. Pauwels, Dec. 2014) and P. whiteheadi was also observed and documented in Sabah, Sepilok (C.C. Lee pers. comm., Fig. 12E). Geckos generally are attracted by sugar-rich food (O. Pauwels pers. comm., 2014).

Although it does not belong to the effusus group, I should also mention that interactions between Pyrops intricatus (Walker, 1857) and Blattodea of the genus Dorylaea have been documented in Sarawak, Mulu National Park (C.C. Lee pers. comm., Fig. 12F).

The unavailabily of such observations for the three other species of the effusus group can probably be explained by the fact that $P$. whiteheadi and $P$. intricatus are present and apparently rather common in several preserved areas (e.g., Danum Valley, Sepilok, Kinabatangan for the first, Mulu for the second) which are extensively visited by naturalists and ecotourists, while the other species are found in more remote regions. All observations reported here come from such sources and it is likely that the same interactions will be documented for the other species in the future.

\section{Discussion}

The present paper illustrates the critical need for taxonomic work in a spectacular and apparently wellknown group of insects. The production of clear, updated and accurately illustrated identification keys, which requires an in-depth revision, including the examination of all types, is necessary to avoid further spreading of erroneous information and wrong identifications which are currently commonplace, e.g., on the internet.

The collaboration with amateur naturalists and nature photographers leads again to very interesting results (see also Constant 2014; Constant \& Alisto 2015): in the present paper, many data on the distribution and biology of the species including all trophobiosis observations come from such "citizen science" sources. Some data also originate from websites and blogs whose authors are unfortunately difficult to track and contact.

Twelve species of Pyrops are currently recorded from Borneo (Nagai \& Porion 1996, 2002, 2004). However, several of them are known from single or very few specimens and the biology, life-history and phenology of all is practically undocumented. Hopefully in the future, with the help of local biologists and citizen-scientists, it will be possible to fill those gaps. This, together with the availability of more material and the clarification of some taxonomical issues (Constant, unpublished), will allow the publication of a comprehensive key to the species of Pyrops from Borneo.

\section{Acknowledgements}

I warmly thank Mrss Kara Norby and Ashley Kennedy, Messrs Joost Woltering, Dave Forney, Martin Hauskrecht, Nicola Messina, Ch'ien C. Lee (www.wildborneo.com.my) and Anton Sorokin for sharing their photographs, observations and/or data, as well as all the persons who published their photographs and data on the internet (listed under "material examined on photographs"); Mr Jonathan Brecko for taking the photographs of the male genitalia; Dr. Hiromi Yoshitomi for sending photographs of the type of P. gunjii; Mrs Jeannine Bortels for the photographs of the specimens in the Lallemand's collection (FSAG); Mr Harold Labrique for the information on Porion's collection (MHNL); Dr Olivier S.G. Pauwels for the identification of the gecko species and Dr George Beccaloni for the Blattodea; 
Messrs Mick Webb and Max Barclay for their help during my visit at BMNH and after. This study has benefitted from funds from the European Union (Synthesys Project - Grant GB-TAF-1642) for a visit to the collection of BMNH in 2011. I thank all the curators listed above for access to the material under their responsibility; my colleagues Dr Patrick Grootaert and Mr Pol Limbourg (RBINS), and Pr. Thierry Bourgoin (MNHN) for their permanent help and support.

\section{References}

Baker C.F. 1925. Remarks on certain Indo-Malayan Fulgora, with special reference to Philippines species. Philippines Journal of Science 28: 343-364.

Blanchard E. 1845. Septième ordre, les Hémiptères. In: Blanchard E. 1845. Histoire des insectes, traitant de leurs moeurs et de leurs métamorphoses en général et comprenant une nouvelle classification fondée sur leurs rapports naturels 2: 424-427.

Bourgoin T. 1997. Habitat and ant-attendance in Hemiptera: a phylogenetic test with emphasis on trophobiosis in Fulgoromorpha. In: Grandcolas P. (ed.) The Origin of Biodiversity in Insects: Phylogenetic Tests of Evolutionary Scenarios. Mémoires du Muséum National d'Histoire Naturelle 173: 109-124. Muséum National d'Histoire Naturelle, Paris.

Bourgoin T. 2015. FLOW (Fulgoromorpha Lists on The Web): A world knowledge base dedicated to Fulgoromorpha. V.8, updated [15 Mar. 2015]. http://hemiptera-databases.org/flow/

Chou I., Wang S. \& Huang J. 1985. Priskribo de novaj specioj de Fulgoroedoj el Cinio (Homopteroj: Fulgoroedoj). Entomotaxonomia 7 (1): 29-38. (in Chinese with abstract in Esperanto).

Constant J. 2004. Révision des Eurybrachidae (I). Le genre Amychodes Karsch, 1895 (Homoptera: Fulgoromorpha: Eurybrachidae). Bulletin de l'Institut royal des Sciences naturelles de Belgique 74: 11-28.

Constant J. 2014. Review of the Oriental lantern-fly genus Egregia Chew Kea Foo, Porion \& Audibert, 2011, with a new species from Sumatra (Hemiptera: Fulgoromorpha: Fulgoridae). European Journal of Taxonomy 92: 1-9. http://dx.doi.org/10.5852/ejt.2014.92

Constant J. \& Alisto L. 2015. Contribution to the knowledge of some Lanternflies of the Philippines (Hemiptera: Fulgoromorpha: Fulgoridae). Belgian Journal of Entomology 27: 1-16.

Distant W.L. 1889. XLIX. Descriptions of new species of Rhynchota collected on or near the Kina Balu Mountain, North Borneo. Annals and Magazine of Natural History (Series 6) 3: 419-422.

Distant W.L. 1891. XXIII. Descriptions of four new species of the genus Fulgora. Transactions of the Entomological Society of London 1891: 517-519.

Duponchel P.A.J. 1840. Essai sur les fulgorelles, par Maximilien Spinola. Revue Zoologique, par la Société cuvierienne; Association Universelle pour l'Advancement de la Zoologie, de l'Anatomie comparée et de la Palaéontologie; Journal mensuel 2: 199-206.

Fölling M., Knogge C. \& Böhme W. 2001. Geckos are milking honeydew-producing planthoppers in Madagascar. Journal of Natural History 35 (2): 279-284. http://dx.doi.org/10.1080/00222930150215378

Guérin-Méneville F.E. 1845. (Fulgora cyanirostris. Guer.). Bulletin de la Société Entomologique de France. (Series 2) 3: 96.

International Commission on Zoological Nomenclature. 1955. Opinion 322. Validation, under the Plenary Powers, of the generic name Fulgora Linnaeus, 1767 (Class Insecta, Order Hemiptera) and designation for the genus so named of a type species in harmony with current nomenclatorial practice. Opinions and Declarations by the Internatinal Commission on Zoological Nomenclature 9 (13): 185-208.

Kemal M. \& Koçak A.Ö. 2012. A report on the mutualism between Hemidactylus (Gekkonidae) and Laternaria (Fulgoridae) in Thailand. Cesa News 82: 15-18. 
CONSTANT C., Fulgoridae: Pyrops effusus species group (Hemiptera)

Kirkaldy G.W. 1902. Memoirs on Oriental Rhynchota. The Journal of the Bombay Natural History Society 14: 46-58. http://biodiversitylibrary.org/page/30157663 [accessed May 2015]

Lallemand V. 1959. Révision des espèces africaines de la famille Fulgoridae (Super-famille Fulgoroides sous-ordre des Homoptères). Publicaçoes Culturais da Companhia de Diamantes de Angola 41: 37-124.

Lallemand V. 1960a. De quibusdam fulgoris. Entomologische Mitteilungen aus dem Zoologischen Staatsinstitut und Zoologischen Museum Hamburg 24: 1-7.

Lallemand V. 1960b. Contribution à l'étude de la Famille Fulgoridae (2ème note). Zeitschrift der Arbeitsgemeinschaft Österreicher Entomologen 12 (3): 138-139.

Lallemand V. 1963. Révision des Fulgoridae (Homoptera). Deuxième partie. Faunes asiatique et australienne. Mémoires de l'Institut royal des Sciences naturelles de Belgique (Series 2) 75: 1-99.

Leong T.M., Murphy D.H. \& Leong L. 2009. Records of the lantern bug, Laternaria oculata (Westwood, 1839) (Homoptera: Fulgoridae: Fulgorinae) in Singapore, with notes on Zanna nobilis (Westwood, 1839). Nature in Singapore 2: 495-501.

Liang A.-P. 1998. Nomenclatorial notes on the Oriental lantern fly genus Pyrops Spinola (Hemiptera: Fulgoroidea: Fulgoridae). Acta Zootaxonomica Sinica 23 (1): 41-47.

Metcalf Z.P. 1947. General Catalogue of the Homoptera. Fascicle IV Fulgoroidea. Part 9 Fulgoridae. North Carolina State College, Raleigh (U.S.A.).

Nagai S. \& Porion T. 1996. Fulgoridae 2: Catalogue illustré des faunes asiatique et australienne. Sciences Nat, Compiègne.

Nagai S. \& Porion T. 2002. Fulgoridae 2. Supplement 1. New Fulgoridae from South-East Asia. Hillside Books, Canterbury.

Nagai S. \& Porion T. 2004. Fulgoridae 2, supplement 2: Nouveaux Fulgoridae d'Asie du Sud-Est. Hillside Books, Canterbury.

Naskrecki P. \& Nishida K. 2007. Novel trophobiotic interactions in lantern bugs (Insecta: Auchenorrhyncha: Fulgoridae). Journal of Natural History 41 (37-40): 2397-2402. http://dx.doi. org/10.1080/00222930701633570

Roth L. \& Naskrecki P. 2001. Trophobiosis between a blatellid cockroach (Macrophyllodromia spp.) and fulgorids (Enchophora and Copidocephala spp.) in Costa Rica. Journal of Orthoptera Research 10: 189-194.

Satô M. \& Nagai S. 1994. Taxonomic notes on the Southeast Asian species of the genus Fulgora (Homoptera: Fulgoridae). Transactions of the Shikoku Entomological Society 20 (3-4): 307-314.

Manuscript received: 27 February 2015

Manuscript accepted: 8 April 2015

Published on: 8 July 2015

Topic editor: Koen Martens

Desk editor: Kristiaan Hoedemakers

Printed versions of all papers are also deposited in the libraries of the institutes that are members of the EJT consortium: Muséum National d'Histoire Naturelle, Paris, France; Botanic Garden Meise, Belgium; Royal Museum for Central Africa, Tervuren, Belgium; Natural History Museum, London, United Kingdom; Royal Belgian Institute of Natural Sciences, Brussels, Belgium; Natural History Museum of Denmark, Copenhagen, Denmark. 